\title{
Filling Characterization into a Section Restriction in Low-Pressure Casting
}

\author{
Antonin Sanitas, Marie Bedel, Mohamed El Mansori \\ MSMP Laboratory (EA-7350), Arts et Métiers ParisTech \\ 2 cours des Arts et Métiers, 13617 Aix en Provence, France \\ antonin.sanitas@ensam.eu; marie.bedel@ensam.eu; mohamed.elmansori@ensam.eu
}

\section{Extended Abstract}

Today, the need of high quality cast components for automotive and aeronautics industries leads to develop the lowpressure casting process [1], [2]. Indeed, the controlled counter gravity flow during mould filling lowers the amount of entrapped gas and oxides. This process consists of a pressurized furnace linked to the mould through a vertical rising tube. The filling is led by gradually increasing the pressure of the gas above the liquid metal. This way, the metal head pressure is compensated and the metal is pushed through the rising tube towards the mould. A velocity above $0,5 \mathrm{~m} / \mathrm{s}$ is experimentally known to induce defects in parts [3].Hence, the gas pressure - metal filling velocity relationship needs to be known to prevent such defects. Previous low-pressure studies used incompressible steady-state Bernoulli's equations to estimate the metal front evolution by assuming that the dynamic pressure of the fluid is negligible [4]-[7]. An analytical expression is then found at every moment linking the metal front height and the gas pressure. On their work, Fan and coworkers found a good correlation between the experimentally measured and the analytically predicted metal front evolution in plate patterns [8]. Nevertheless, in the example of an automotive industrial part studied by Hogg and co-workers [9], the measured filling velocity is lower than expected according to this simple analytical model. Moreover, testing a sudden horizontal section increase in a mould has been proven to induce oscillations that increase in amplitude when increasing the pressure ramp [7]. Therefore, the existing studies on filling flow in low pressure casting do not permit to establish clearly the relationship between mould geometry and metal front rising.

This work proposes a characterization of the imposed gas pressure - metal flow velocity relationship in low pressure casting. More precisely, the relative effect of local and global horizontal section changes on filling flow is studied. To do so, experimentally measured and numerically predicted metal front position evolutions are compared in the case of different mould geometries. An $\mathrm{AlSi}_{13}$ alloy is melt and poured by low pressure casting in 3D printed sand moulds. A $25 \mathrm{mbar} / \mathrm{s}$ pressure ramp is set for filling. Three different geometries are studied with an identical global horizontal section restriction of 0.24: one cylinder, six cylinders and one ring. To track the experimental metal height evolution, electrical contacts are used. Experimental metal height versus time curves are extracted and reveal an oscillating phenomenon after section changing. Due to this phenomenon, an over-height which is not predicted by the analytical equations is observed. The velocity of the flow reaches values above $0.5 \mathrm{~m} / \mathrm{s}$, leading to risks of defects. The experimental cases are then simulated using ANSYS Fluent ${ }^{\circledR}$ simulation software. A k-epsilon flow model simulates the whole low pressure system the metal in the mould, in the tube and in the furnace and the pressuring gas-. The observed filling oscillations are compared to the oscillations predicted by the model in terms of maximal overweight and velocity for the three studied geometries. A relationship between local and global horizontal section restriction factor and oscillations is proposed. It will allow us to define reliable rules of mould design for limiting turbulence and reaching sound quality in low pressure casting.

\section{References}

[1] F. Bonollo, J. Urban, B. Bonatto, M. Botter, "Gravity and low pressure die casting of aluminium alloys: a technical and economical benchmark," La Metall. Ital., no. 6, pp. 23-32, 2005.

[2] J. Duan, D. Maijer, S. Cockcroft, C. Reilly, "Development of a 3D Filling Model of Low-Pressure Die-Cast Aluminum Alloy Wheels," Metall. Mater. Trans. A, vol. 44, no. 12, pp. 5304-5315, 2013.

[3] J. Campbell, CASTINGS. Elsevier Science, 2003. 
[4] E. S. Duff, "Fluid Flow Aspects of Solidification Modelling : Simulation of Low Pressure Die Casting," 1999.

[5] H. Puga, J. Barbosa, T. Azevedo, S. Ribeiro, and J. L. Alves, "Low pressure sand casting of ultrasonically degassed Al7SiMg alloy: Modelling and experimental validation of mould filling," Mater. Des., vol. 94, pp. 384-391, 2016.

[6] P. Fu, A. a. Luo, H. Jiang, L. Peng, Y. Yu, C. Zhai, A. K. Sachdev, "Low-pressure die casting of magnesium alloy AM50: Response to process parameters," J. Mater. Process. Technol., vol. 205, no. 1-3, pp. 224-234, 2008.

[7] S.-G. Liu, F.-Y. Cao, X.-Y. Zhao, Y.-D. Jia, Z.-L. Ning, J.-F. Sun, "Characteristics of mold filling and entrainment of oxide film in low pressure casting of A356 alloy," Mater. Sci. Eng. A, vol. 626, pp. 159-164, 2015.

[8] Z.-T. Fan and S. Ji, "Low pressure lost foam process for casting magnesium alloys," Mater. Sci. Technol., vol. 21, no. 6, pp. 727-734, 2005.

[9] J. C. Hogg, H. Westengen, D. L. Albright, "Low pressure sand casting of magnesium alloys," in Proceedings of the International Symposium on Extraction, Refining and Fabrication of Light Metals, Ottawa, 1991. 